Boletín de la Sociedad Geológica Mexicana

Número Especial de Geología Urbana

Tomo LVIII, NúM. 2, 2006, P. iii-iv

\title{
Editorial:
}

\section{Una nueva etapa para el Boletín de la Sociedad Geológica Mexicana}

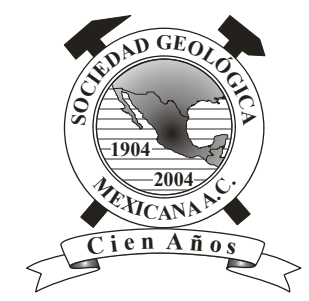

\author{
Antoni Camprubí ${ }^{1,2, *}$, Susana A. Alaniz-Álvarez ${ }^{1}$ \\ ${ }^{1}$ Centro de Geociencias, Universidad Nacional Autónoma de México, Campus Juriquilla, \\ Carretera 57 km 15.5, 76023 Santiago de Querétaro, Qro., México \\ ${ }^{2}$ Instituto de Geofísica, Universidad Nacional Autónoma de México, \\ Ciudad Universitaria, 04510 México, D.F., México \\ *camprubi@geociencias.unam.mx.
}

Tras la edición exitosa de los cuatro volúmenes del Boletín de la Sociedad Geológica Mexicana conmemorativos del centenario de la SGM, editados entre 2005 y 2006, es preciso replantearnos el desarrollo futuro del Boletín. Éste pasa por hallar un espacio propio, distinto y distintivo del que ya cubre la Revista Mexicana de Ciencias Geológicas (RMCG). Desde el Comité Editorial actual y pasado del Boletín tenemos la convicción que las dos revistas no tienen por qué entrar en una competencia y que, lejos de ello, pueden complementarse.

En la RMCG se vienen publicando desde hace varios años trabajos de investigación original en todos los campos de las Ciencias de la Tierra, generalmente de alcance regional y en que se presentan datos obtenidos mediante un conjunto de técnicas o procedimientos cuyo objeto es la obtención de explicaciones unitarias, esto es, que sirven a un propósito concreto. La consecuencia inmediata de la inclusión de esta revista en el Science Citation Index ha sido el aumento considerable de artículos sometidos a ésta, absorbiendo artículos que otrora hubieran sido sometidos tanto a revistas internacionales como a revistas nacionales (como Geofísica Internacional o el propio Boletín). Sin embargo, el Boletín no ha resentido tal impacto en forma disminución de artículos sometidos debido a la edición del Volumen del Centenario y del presente volumen especial sobre estudios de Geología Urbana. Sin embargo, ¿cuál es el panorama que le espera al Boletín después de éste?

El Boletín de la Sociedad Geológica Mexicana es una revista científica arbitrada, publicada desde el año 1904, lo que la convierte en una de las revistas científicas activas en publicación más antiguas de México y de las Américas. A pesar de su inactividad entre 1913 y 1936, se han editado 58 volúmenes. Sigue siendo una necesidad, sin embargo, garantizar la periodicidad del Boletín año tras año sin rebajar de calidad sus contenidos y permaneciendo como un punto de referencia útil en el estudio de las Ciencias de la Tierra en México.
Por todo ello, se tomó la decisión, entre el Comité Editorial saliente y el entrante, de abrir el Boletín a tipos de artículo pocas veces contemplados en revistas de Ciencias de la Tierra arbitradas y editadas en México. Así, se propone articular los contenidos del Boletín en base a (1) una ampliación de sus áreas temáticas, (2) una ampliación de las áreas de trabajo, (3) una ampliación tipológica de los artículos sometibles, (4) una redefinición de los contenidos de los artículos, (5) su publicación como boletín electrónico de acceso libre, y (6) la coordinación editorial permanente entre el Boletín y la RMCG.

Las áreas temáticas en que se se proponía que el Boletín recibiera contribuciones dentro de sus normas editoriales eran un tanto escasas. El ámbito natural del Boletín son integralmente las Ciencias de la Tierra. En las normas editoriales actuales se solicitan expresamente contribuciones en las disciplinas de geología regional, mineralogía y petrología, metalogénesis y yacimientos minerales, geología del petróleo, geotermia, hidrología, geología marina, edafología, estratigrafía, paleontología, geobiología, geofísica, sismología, geoquímica, volcanología, tectónica y geología estructural, geomorfología, geología planetaria, meteorítica, geotecnia e ingeniería geológica, geología del Cuaternario, geoarqueología, y geología urbana, aunque cualquier disciplina en Ciencias de la Tierra tiene cabida en el Boletín. Algunas de estas disciplinas ya cuentan con revistas de su propio ámbito, pero no la mayoría de ellas; en especial, disciplinas como la geotecnia e ingeniería geológica, geología del Cuaternario, geoarqueología, y la geología urbana han carecido históricamente de un ámbito de expresión entre las revistas científicas de México, una carencia que es preciso solventar.

Cabe destacar que el ámbito temático del Boletín no se restringe a México en sí: dado que la geología no conoce fronteras, tampoco debe de hacerlo ninguna revista en Ciencias de la Tierra. Las áreas de trabajo en que potencialmente pueden recibirse contribuciones para el Boletín 
no deben de ser sólo México y su entorno inmediato, sino también el resto de las Américas, la "Espina Dorsal de las Américas" (Cordillera, Andes, Sierra Madre, etc.), el Caribe y el Golfo de México, o el Océano Pacífico. Igualmente deseables son estudios del volcanismo terciario a reciente, del basamento precámbrico, de paleogeografía o paleoclimatología, sobre el Márgen Circumpacífco, sobre el registro paleontológico, o sobre cualquier tema que tenga relación con las incógnitas geológicas de México, aunque el área de trabajo concreta se encuentre geográficamente lejana de éste.

Además de artículos de corte "clásico", sería deseable que el Boletín recibiera trabajos de revisión temática, artículos de difusión o divulgación, notas o comunicaciones cortas de carácter técnico, notas o comunicaciones rápidas, notas sobre temas de actualidad geológica, reseñas de libros, bases de datos etc. Todos ellos son tipos de trabajos que pueden tener cabida en el Boletín, pues generalmente carecen de medios de difusión adecuados. Las revistas científicas tienen que acabar doblegándose a las necesidades de los estudiantes y los académicos, sometidos a la exigencia o a la costumbre de tener que acumular artículos de un corte muy determinado, lo cual provoca que se descuiden otro tipo de publicaciones necesarias y útiles para los más diversos propósitos académicos.

Sin embargo, no podemos restringir el espacio de publicación del Boletín a meras tipologías de artículos. También es preciso definir su alcance temático. Así, trabajos originales de alcance local, de aplicación o implementación de una técnica concreta, de aplicación limitada de una o más técnicas, de investigación aplicada, artículos derivados de tesis de licenciatura o de maestría (que tan frecuentemente permanecen totalmente inéditas), itinerarios geológicos etc., pueden tener una cabida en el Boletín que otras revistas mexicanas como la RMCG ya no pueden permitirse. Ello, sin embargo, no obra en perjuicio de la publicación de artículos científicos largos de corte clásico, pues nuestra intención es precisamente de abrir el Boletín, no de limitarlo en sus funciones y posibilidades. Se alienta especialmente la interdisciplinariedad y transdisciplinariedad de sus contribuciones. A pesar de que el Boletín completo está disponible en versión electrónica e impresa, y en los últimos años se ha venido realizando ambas ediciones de forma simultánea, en lo sucesivo se editará únicamente como revista electrónica, a reserva de que uno o varios volúmenes puedan ser editados en versión impresa, en función del interés de los lectores y de la disponibilidad de financiamiento al caso. Así, el Boletín será una revista de acceso libre. Un boletín electrónico tiene la ventaja de que los artículos aceptados para publicación pueden ser publicados de forma inmediata en la red a partir de su paso por edición técnica, así como una mayor inclusión de páginas a color que las ediciones en papel. Como ejemplo del potencial de difusión que puede tener el Boletín como revista electrónica, basta consultar la lista en línea de los 25 artículos más descargados durante el año pasado.

Nada más queda agregar que, como en tiempos de cambio se aprovecha para cambiar más cosas que las previstas, también cambió la cara, la portada del Boletín, a partir de este número. Ésta incorporará en cada número una foto nueva a toda página. 